\title{
SEASONAL PATTERNS OF LEAF PHOTOSYNTHETIC CAPACITY IN SUCCESSIONAL NORTHERN HARDWOOD TREE SPECIES ${ }^{1}$
}

\author{
THOMAS W. JURIK ${ }^{2}$ \\ University of Michigan Biological Station, Ann Arbor, Michigan 48109-1048
}

\begin{abstract}
A B S T R A C T
Seasonal patterns of leaf photosynthetic capacity and conductance were determined for deciduous hardwood tree species in natural habitats in northern lower Michigan. Leaves of bigtooth aspen and red oak at the top of the canopy had higher maximum $\mathrm{CO}_{2}$ Exchange Rate (CER) (10-15 $\mu \mathrm{mol} \mathrm{m}^{2} \mathrm{~s}^{1}$ ) than leaves of sugar maple, red maple, red oak, and beech growing in the

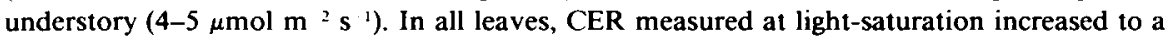
maximum near the completion of leaf expansion in early June, was constant until mid-September, and then rapidly declined until leaf death. A similar pattern was seen for CER measured in low light ( $1.5 \%$ full sun). Respiration rate in the dark was highest in young leaves and decreased during leaf expansion; a relatively constant rate was then maintained for the rest of leaf lifespan. The seasonal pattern of the initial slope of the light response of CER paralleled the pattern of light-saturated CER. The initial slope in midsummer ranged from values of 37 to $44 \mu \mathrm{mol} / \mathrm{mol}$ for species in the understory to 51 and $56 \mu \mathrm{mol} / \mathrm{mol}$ for red oak and bigtooth aspen, respectively, at the top of the canopy. Leaf conductance was constant throughout most of leaf lifespan, with some decline occurring in autumn. Leaves at the top of the canopy had higher conductances for water vapor $(2-5 \mathrm{~mm} / \mathrm{s})$ than leaves in the understory $(1-2 \mathrm{~mm} / \mathrm{s})$. All species maintained leaf intercellular $\mathrm{CO}_{2}$ mole fractions $\left(c_{i}\right)$ near $200 \mu \mathrm{L} / \mathrm{L}$ until autumn, when $c_{i}$ increased during leaf senescence.
\end{abstract}

A BASIC PROBLEM facing many field investigations in biology is the confounding of time of sampling with the experimental treatment being tested. For example, characterization of the response of photosynthesis to four or five environmental factors must inevitably be spread over a considerable period, since at best the response to changes in only one or two factors can be measured at a time. Definition of an entire multi-dimensional "response surface" thus requires extensive sampling over weeks or months. Does the photosynthetic capacity of a leaf change over such a measurement interval? Some evergreen species retain near-maximal leaf photosynthetic capacity for two or more years (Chabot and Hicks, 1982). In contrast, many herbaceous species maintain maximum leaf photosynthetic capacity for only a few days; capacity then steadily declines over the remainder of the leaf's lifetime (Jurik, Chabot, and Chabot, 1979). However, little is known of the effect of time and age on photosynthetic capacity of deciduous hardwood tree species growing under natural conditions.

\footnotetext{
${ }^{1}$ Received for publication 22 April 1985; revision completed 19 August 1985.

2 Present address: Department of Botany, Iowa State University, Ames, IA 50011.

I thank Jeff Axelrod and Bruce Gaynor for assistance with the field work. Supported by the United States Department of Energy under contract DE-ACO2-79EV10091.
}

Seasonal patterns of photosynthetic capacity were determined here as a prelude to more extensive investigations of environmental effects on photosynthetic performance of tree leaves in the field. The determination of seasonal patterns of photosynthetic capacity also provides insight into the evolution of temporal patterns of photosynthetic capacity among species of different growth forms.

Methods-Field sites were located at the University of Michigan Biological Station near Pellston, Michigan $\left(45^{\circ} 33^{\prime} \mathrm{N}, 84^{\circ} 42^{\prime} \mathrm{W}\right)$. The original forest was completely removed by logging and burning by 1909. The Upper Grapevine site (elev. $235 \mathrm{~m}$ ) presently supports a successional forest dominated by bigtooth aspen (Populus grandidentata Michx.), with paper birch (Betula papyrifera Marsh.), northern red oak (Quercus rubra L.), and red maple (Acer rubrum L.) also present in the overstory canopy. Average height of trees in the overstory was approximately $15 \mathrm{~m}$. Soil on the site was a Roselawn sand (U.S. Soil Survey). The Grapevine Trail site (elev. $221 \mathrm{~m}$ ) was $80 \mathrm{~m}$ east of the Upper Grapevine site; the site sloped gently to the east. The soil was an Emmet loamy sand. The Grapevine Trail site supported a greater number of species, especially in the understory, than did the Upper Grapevine site; all species present at Upper Grapevine were 
represented at Grapevine Trail, although in lesser abundance. Sugar maple (Acer saccharum Marsh.) and red oak were the most common woody understory species, with beech (Fagus grandifolia Ehrh.), striped maple (Acer pennsylvanicum L.), basswood (Tilia americana L.), and several other species also present.

All deciduous tree species on the study sites produced only a single set of leaves, during a relatively short period in late spring. Aspen has an indeterminate pattern of leaf production on many sites over its entire range of habitats. Although young aspen sprouts on recently cleared areas at the Biological Station may exhibit continuous production of leaves throughout the summer, older aspen stems produce only a single set of leaves, possibly because of the relatively low fertility of the soils in this region. This study thus dealt with leaves all produced in late spring and all dying in autumn. Leaf expansion of all species except aspen typically was completed before June, whereas aspen leaf expansion often was not completed until the second or third week of June.

Gas exchange of single, attached leaves was monitored using a mobile laboratory at the field sites. Leaves from 0.5 to $1.5 \mathrm{~m}$ above ground, on seedlings and small saplings, were sampled at Grapevine Trail. At Upper Grapevine, a tower made of scaffolding material allowed use of leaves growing in almost full sunlight near the top of the canopy, 12 to $14 \mathrm{~m}$ aboveground. The gas exchange measurement system was an open-circulation system with an infrared $\mathrm{CO}_{2}$ gas analyzer, as described in Jurik, Weber, and Gates (1984). Measurements were made in ambient $\mathrm{CO}_{2}$ and $\mathrm{O}_{2}$ levels. Data are largely from experimental runs, made at all times of day, in which light and temperature were controlled; some data from daily-time courses of gas exchange, in ambient light and with the leaf temperature controlled to match ambient air temperature, are also included. Measurements of temperature response of lightsaturated $\mathrm{CO}_{2}$ exchange rate (CER) suggested that the optimal temperature for all species was between 20 and $25 \mathrm{C}$, with little or no change in temperature optimum during the growing season (Jurik, unpublished data). Data presented here for CER in both high and low light were from measurements between 20 and 25 $C$, even though optimal temperature for CER in low light may be lower than the optimum in high light. Dark respiration rates were measured after 30 to 90 minutes in the dark, at 20 to $25 \mathrm{C}$, and thus are not actual nighttime rates. Severely water-stressed leaves that exhibited signs of stomatal closure, as indicated by great- ly reduced transpiration, were not included in the data presented here. However, some of the variation in the data, especially in July and August, is undoubtedly due to the effects of mild water stress.

Leaf areas were measured with a LICOR Model 3000 leaf area meter; leaf dry weight was determined after drying to constant weight in an oven at $70 \mathrm{C}$. Stomatal conductance to water vapor was calculated from the transpiration rate and water vapor concentration gradient between leaf and air (von Caemmerer and Farquhar, 1981). Intercellular $\mathrm{CO}_{2}$ mole fraction was calculated from the $\mathrm{CO}_{2}$ exchange rate, the mole fraction of $\mathrm{CO}_{2}$ in the gas exchange chamber, and the stomatal conductance to $\mathrm{CO}_{2}$, which was calculated as the conductance to water vapor divided by 1.56 . Initial slope of the light response of CER was determined from data with photosynthetic photon flux density (PPFD, 400-700 $\mathrm{nm}$ ) between 0 and $80 \mu \mathrm{mol} \mathrm{m} \mathrm{m}^{-2} \mathrm{~s}^{-1}$; light level was sequentially increased from dark to higher levels. Leaf temperature for a given leaf was maintained to within $1 \mathrm{C}$ of the nominal measurement temperature, which varied between 20 and 25 $C$ for different leaves.

Results-Seasonal patterns of CER are shown in Fig. 1 for sugar maple in the understory at GRTR. Parts $a, b$, and c of the figure show CER at light-saturation, at low light, and in the dark, respectively. The low light values are at a PPFD of $30 \mu \mathrm{mol} \mathrm{m} \mathrm{m}^{2} \mathrm{~s}^{-1}$, in the range

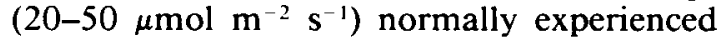
during the day in the shaded understory. These patterns of CER are based on "potential" rates (i.e., rates measured in a constant set of favorable conditions); actual rates in a given $\mathrm{mi}$ crohabitat will depend on actual environmental conditions at any point in time. The spring of 1983, and hence leaf expansion, was delayed by about 10 days, relative to 1981 and 1982 .

Sugar maple (especially seedlings in the understory) was the first tree species to produce leaves in the spring. Leaves appeared in the second week of May and completed their expansion in the last week of May. Maximum light-saturated CER (Fig. 1a) increased during leaf expansion and was then maintained through mid-September, when there was a sharp decline during leaf senescence. The decline in autumn was probably more abrupt for any single leaf than is suggested by the composite data of Fig. 1a; variation among leaves in onset of senescence contributes to the scatter among the values in late September and suggests a more gradual decline of CER than may actually occur. In low light (Fig. 1b), CER fol- 


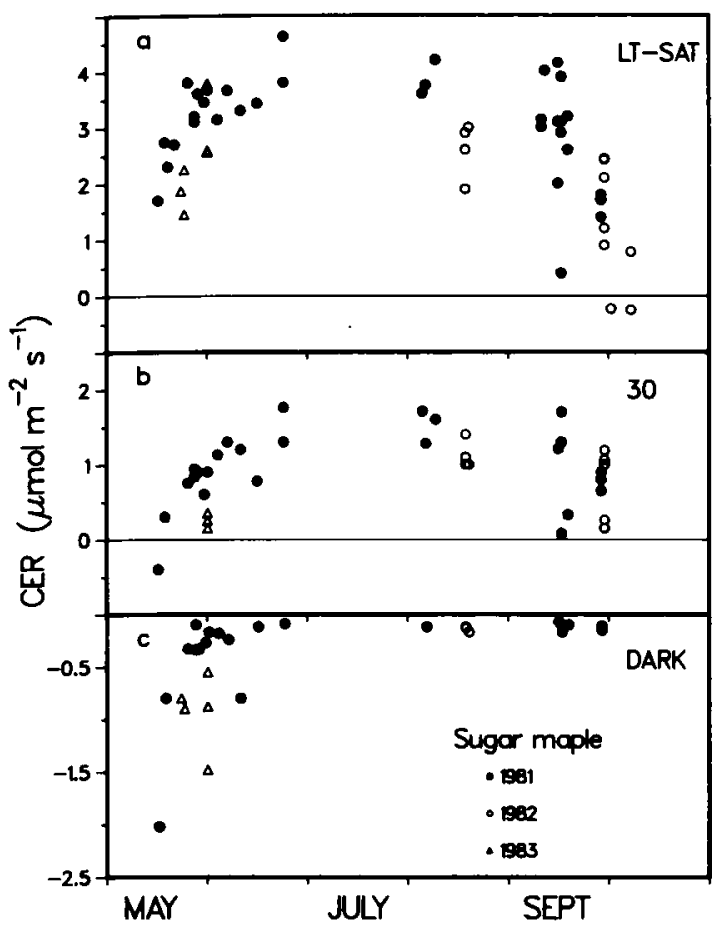

Fig. 1. Seasonal time-course of photosynthetic capacity of sugar maple leaves in a shaded, understory environment (Grapevine Trail forest). CER was measured at leaf temperatures of 20 to $25 \mathrm{C}$ in ambient $\mathrm{CO}_{2}(320-340$ $\mu \mathrm{L} / \mathrm{L}$ ). a) CER at light-saturation, i.e., photosynthetic photon flux density (PPFD, 400-700 nm) of 1,000 to 2,000 $\mu \mathrm{mol} \mathrm{m}^{2-2}{ }^{1}$, b) CER at PPFD of $30 \mu \mathrm{mol} \mathrm{m}{ }^{2} \mathrm{~s}^{1}$, c) CER in the dark.

lowed a pattern similar to that of CER in high light. Dark respiration was very high in young leaves but declined during leaf expansion, presumably as growth respiration declined (Fig. 1c). A fairly constant dark respiration capacity was then maintained throughout the remainder of the growing season. The amount of variation among leaves sampled over any given period of days was approximately the same throughout the growing season (Fig. 1). This variation was due to a multitude of uncontrolled factors such as time of day, water stress, and different growth conditions in different microsites and in different years. The lower values for CER in August, 1982 (Fig. 1a), for example, were probably due to effects of water stress, since conductance values of those leaves were low (see Fig. 7a). The basic pattern of the effects of age appears despite the other environmental effects, however.

Leaves of red oak in the understory appeared five to ten days later in the spring than leaves of sugar maple, but otherwise exhibited patterns of CER (Fig. 2) similar to those of sugar maple. Red oak retained its leaves longer in

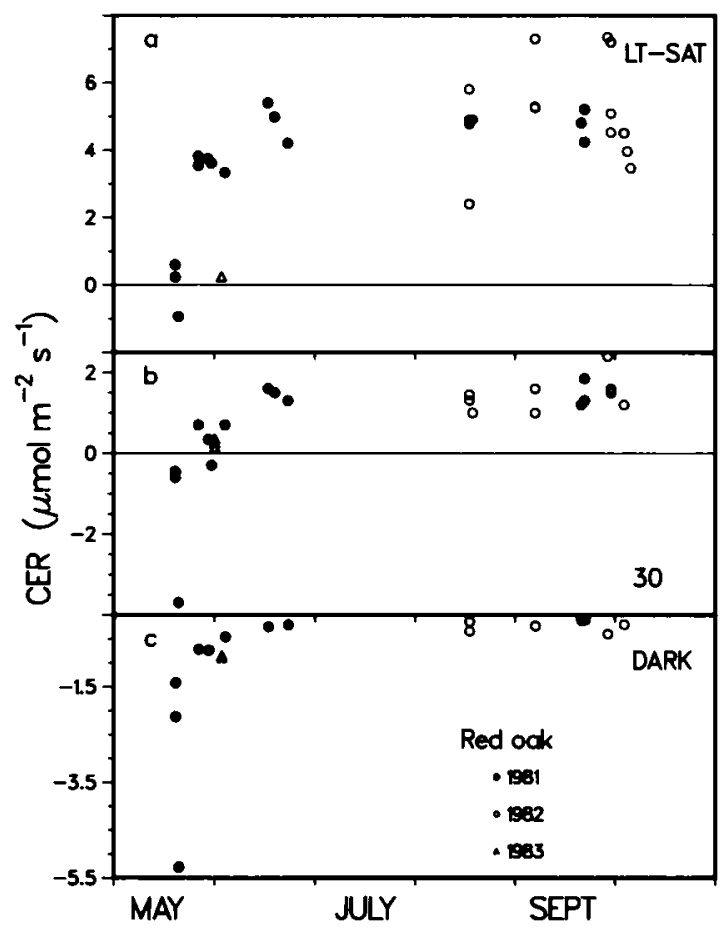

Fig. 2. Seasonal time-course of photosynthetic capacity of red oak leaves in a shaded, understory environment (Grapevine Trail forest). Experimental conditions are as in Fig. 1.

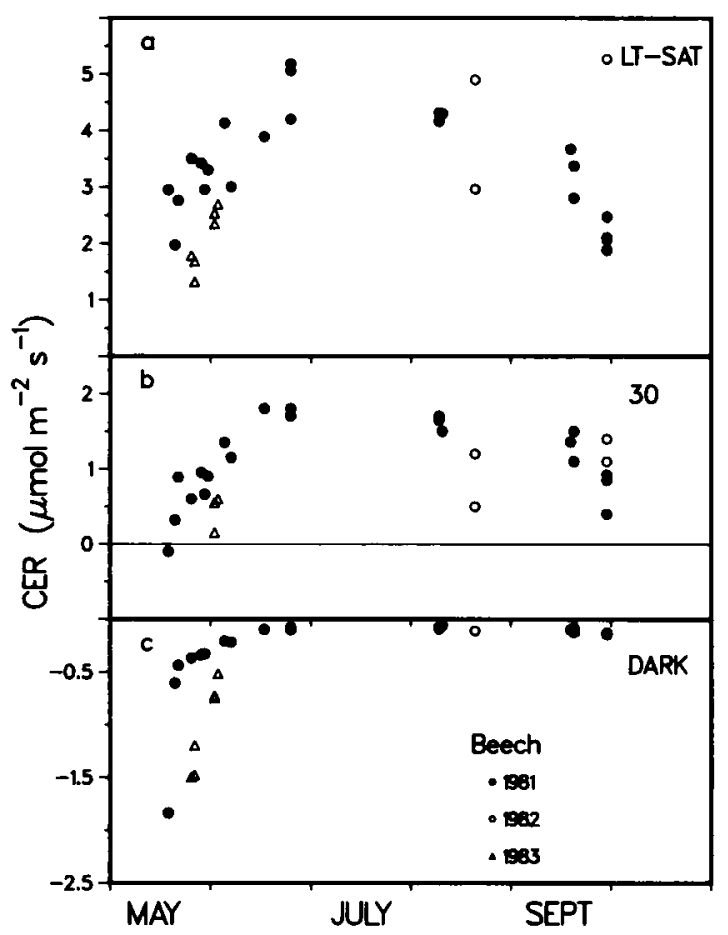

Fig. 3. Seasonal time-course of photosynthetic capacity of beech leaves in a shaded, understory environment (Grapevine Trail forest). Experimental conditions are as in Fig. 1. 


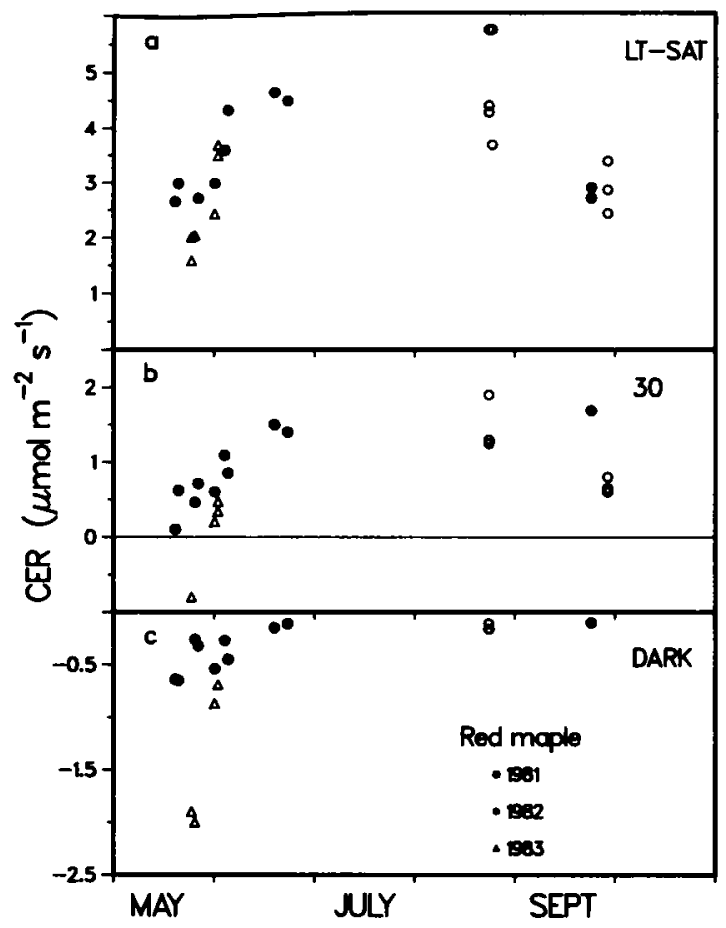

Fig. 4. Seasonal time-course of photosynthetic capacity of red maple leaves in a shaded, understory environment (Grapevine Trail forest). Experimental conditions are as in Fig. 1.

the autumn than practically all other deciduous species; the leaves were indeed metabolically active later in the fall, as indicated by the high CER in early October (cf. sugar maple in Fig. 1).

Seasonal patterns of $\mathrm{CO}_{2}$ exchange capacity for beech and red maple in the understory are shown in Fig. 3, 4, respectively. These two species were similar to sugar maple; CER in high and in low light increased during leaf expansion in spring, was maintained constant over most of leaf lifespan, and declined in late September. Again, dark respiration was highest in young, expanding leaves.

Bigtooth aspen typically was the last deciduous tree species to produce leaves; leaves appeared the last week of May or first week of June and did not complete expansion until the third week of June. The seasonal patterns of CER for bigtooth aspen leaves at the top of the canopy (Fig. 5) generally matched those shown by species in the understory. Aspen had the highest maximum CER of all species studied.

Although produced earlier than bigtooth aspen leaves, red oak leaves at the top of the canopy expanded somewhat later than red oak leaves in the understory. Red oak at the top of the canopy also maintained a fairly constant

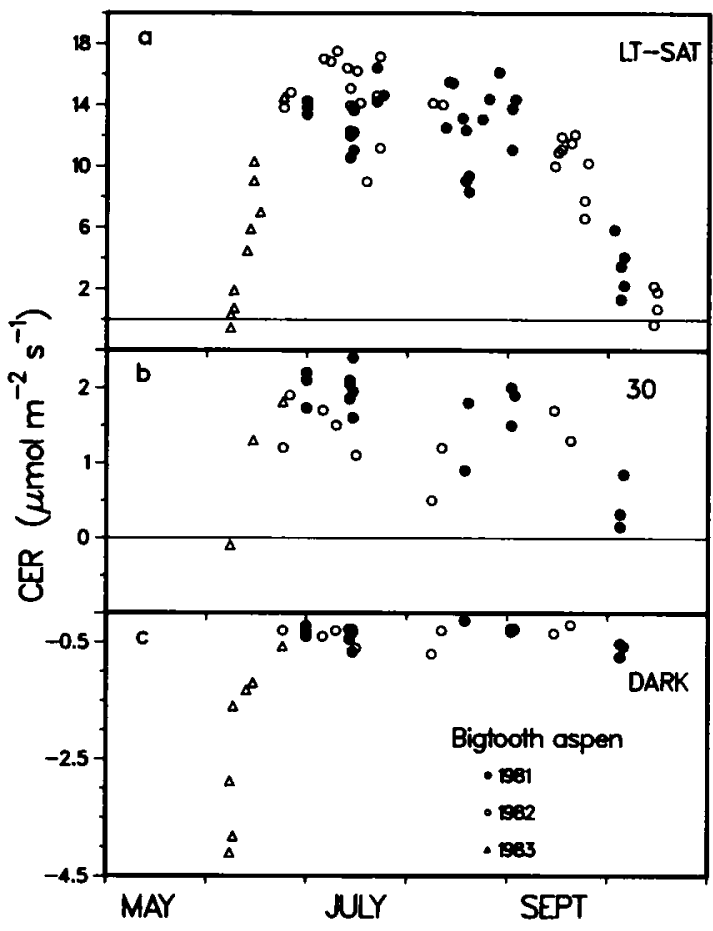

Fig. 5. Seasonal time-course of photosynthetic capacity of bigtooth aspen leaves at the top of the canopy (Upper Grapevine forest). CER was measured at leaf temperatures of 20 to $25 \mathrm{C}$ in ambient $\mathrm{CO}_{2}(320-340 \mu \mathrm{L} / \mathrm{L})$. a) CER at light-saturation, i.e., PPFD of 1,600 to $2,000 \mu \mathrm{mol} \mathrm{m} \mathrm{m}^{-2}$

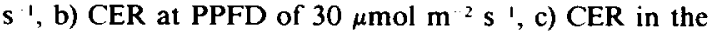
dark.

photosynthetic capacity over the growing season (Fig. 6). Maximum rates were higher in the high-light grown leaves at the top of the canopy than in understory leaves, an acclimatory response to light found in most plants. As in the understory, red oak at the top of the canopy maintained its photosynthetic capacity further into October than did the other species. Red oak leaves measured in 1981 had generally lower CER than leaves measured in 1982 and 1983, apparently because the 1981 leaves were functionally not quite in full light at the top of the canopy due to taller adjacent trees. Even so, the subsets of leaves for 1981 and 1982 showed similar constancy of CER over the summer (Fig. 6).

Since CER at low light and at light saturation were relatively constant over most of leaf lifespan (see above), the overall shape of the light response curve of CER for each species at a given location probably did not change much with time. The initial slope of the light response curve (CER vs. PPFD, $\mathrm{mmol} / \mathrm{mol}$ ) for all species generally paralleled the patterns of CER in high and low light (data not shown). In 


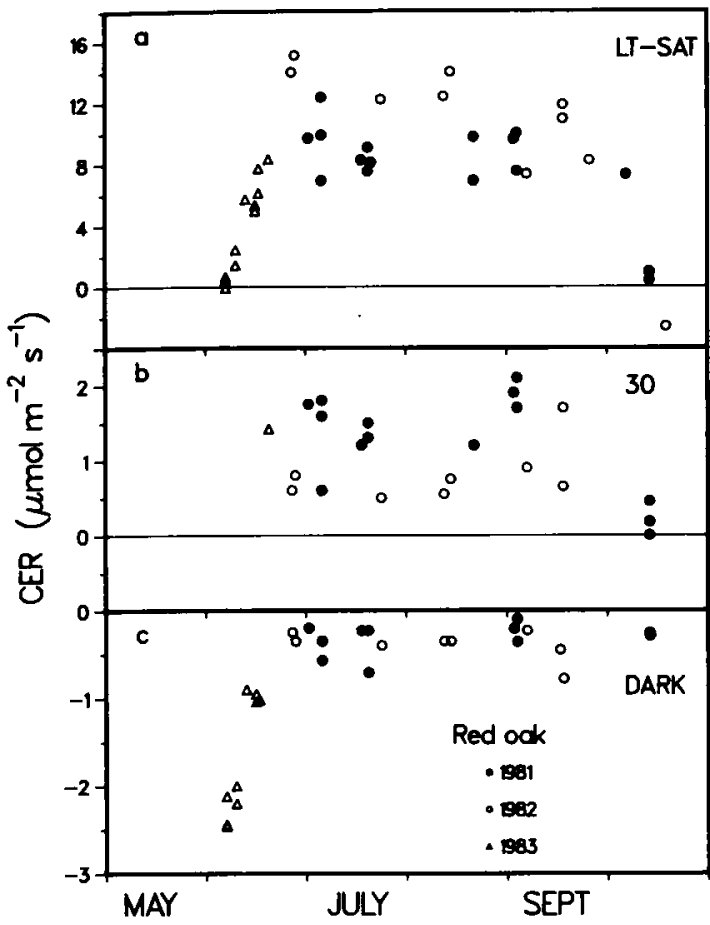

Fig. 6. Seasonal time-course of photosynthetic capacity of red oak leaves at the top of the canopy (Upper Grapevine forest). Experimental conditions are as in Fig. 5.

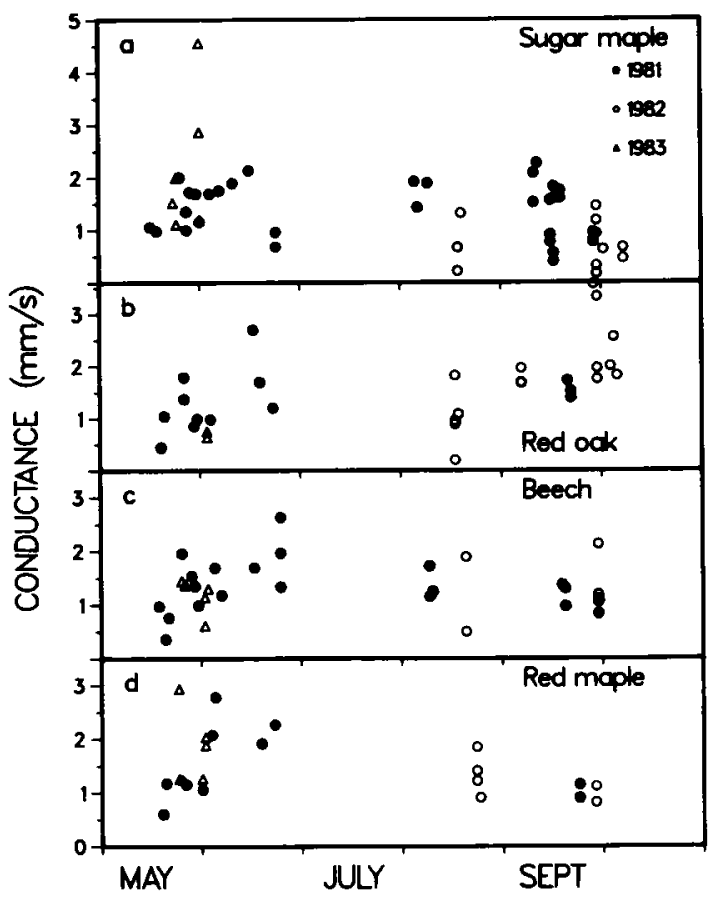

Fig. 7. Seasonal patterns of leaf conductance to water vapor for leaves in the understory at Grapevine Trail. Conductance values are from leaves measured in high light (see Fig. 1 for experimental conditions). a) sugar maple, b) red oak, c) beech, d) red maple.

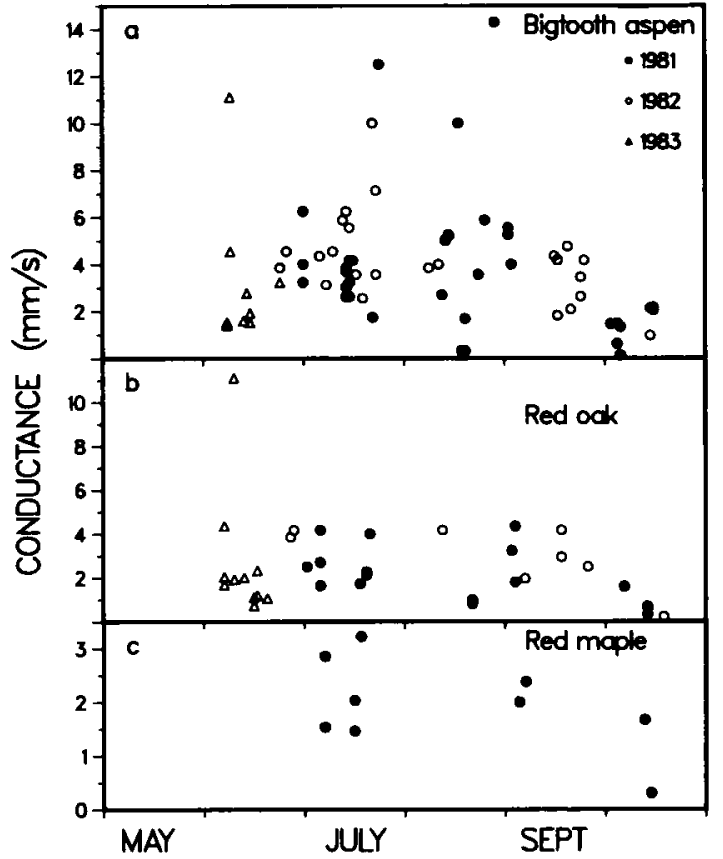

Fig. 8. Seasonal patterns of leaf conductance to water vapor for leaves at the top of the canopy at Upper Grapevine. Conductance values are from leaves measured in high light (see Fig. 5 for experimental conditions). a) bigtooth aspen, b) red oak, c) red maple.

understory leaves during summer, the initial slope was lowest in sugar maple $(37 \mathrm{mmol} /$ $\mathrm{mol})$ and beech $(39 \mathrm{mmol} / \mathrm{mol})$, while red oak had a slightly higher slope $(44 \mathrm{mmol} / \mathrm{mol})$. Bigtooth aspen at the top of the canopy had the highest initial slope $(56 \mathrm{mmol} / \mathrm{mol})$; red oak leaves at the top of the canopy had only a slightly higher initial slope $(51 \mathrm{mmol} / \mathrm{mol})$ than red oak leaves in the understory.

Leaf stomatal conductance to water vapor (and hence to $\mathrm{CO}_{2}$ ) in high light was relatively constant throughout leaf lifespan for all species at both sites, with some decline occurring in leaves undergoing senescence in autumn (Fig. $7,8)$. There was considerable variation at all times of year, reflecting the varied histories of leaves used for measurements at different times. Leaves in the understory (Fig. 7) generally had lower conductances than leaves at the top of the canopy. This was true both among species and within a species (e.g., red oak, red maple). In the understory, sugar maple, beech, red maple, and red oak all had similar values of conductance, although there was considerable variation among samples (Fig. 7). At the top of the canopy, bigtooth aspen had the highest conductance, with red oak and red maple lowest (Fig. 8).

Regressions of light-saturated CER vs. sto- 


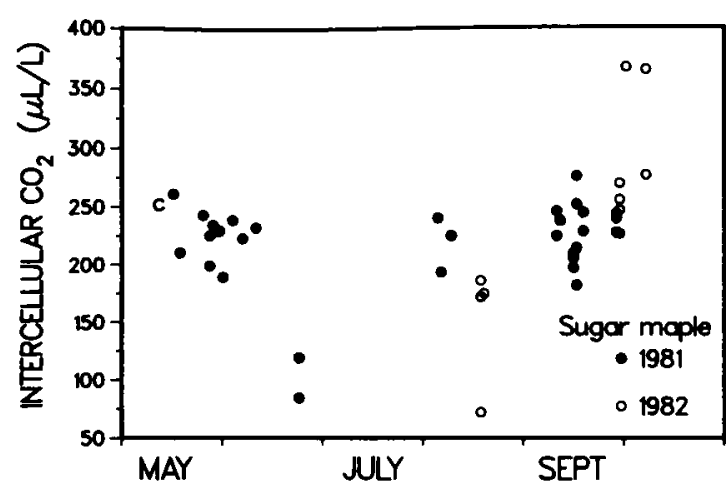

Fig. 9. Seasonal pattern of intercellular $\mathrm{CO}_{2}$ mole fraction $\left(c_{1}\right)$ for sugar maple in the understory at Grapevine Trail. Values are from leaves measured in high light (see Fig. 1 for experimental conditions).

matal conductance to water vapor had statistically significant positive slopes for all species and growth conditions, but low $r^{2}$ values $(0.14$ to 0.63 ) suggested that factors other than conductance exerted considerable control over CER (data not shown).

Intercellular $\mathrm{CO}_{2}$ mole fraction $\left(\mathrm{c}_{\mathrm{i}}\right)$ varied little over most of the growing season; Fig. 9 shows an example, for sugar maple in the understory. In sugar maple, $c_{i}$ was relatively constant, with some low values in late June and mid-August apparently due to low stomatal conductance (cf. Fig. 7). However, low values of stomatal conductance in leaves undergoing senescence in late September (Fig. 7) did not lead to lower $c_{i} ; c_{i}$ actually rose after mid-September (Fig. 9). This pattern indicates that loss of intracellular photosynthetic capacity was in large part responsible for the decline in CER of senescing leaves, although the concurrent decline in conductance may also have limited CER to some extent. A similar pattern was seen in all the other species studied; Table 1 summarizes values of $c_{i}$ before and during leaf senescence. Mean summertime values of $c_{i}$ were always lower than $c_{i}$ during leaf senescence, both for leaves in the understory and in the canopy.

Discussion-Most previous studies of the effect of leaf age on photosynthetic capacity have examined herbaceous species of agronomic importance, although some wild species growing in their natural habitats (e.g., Johnson and Caldwell 1974, Mooney et al., 1981; Field, Merino and Mooney, 1983; Whale, 1983) or in laboratory environments (e.g., Ludlow, 1975; Jurik et al., 1979; Longstreth, Bolaños, and Goddard, 1985) have also been studied. These
TABLE 1. Mean leaf intercellular $\mathrm{CO}_{2}$ mole fraction $\left(c_{i}\right.$, $\mu L / L)$ before and after the middle of September, i.e., before leaf senescence and during leaf senescence, respectively. The 'signif' column shows the results of a one-sided t-test for $c_{1}$ during senescence greater than $c_{1}$ before senescence ${ }^{*}=P<0.05 ; n s=$ not significantly different)

\begin{tabular}{|c|c|c|c|c|c|c|c|}
\hline & \multicolumn{3}{|c|}{ Before senescence } & \multicolumn{4}{|c|}{ During senescence } \\
\hline & $\bar{x}$ & S.D. & $n$ & $\bar{x}$ & S.D. & $n$ & Signif \\
\hline \multicolumn{8}{|l|}{ Understory } \\
\hline \multicolumn{8}{|l|}{ Sugar } \\
\hline Red oak & 178 & 33 & $\begin{array}{l}23 \\
14\end{array}$ & $\begin{array}{l}245 \\
224\end{array}$ & $\begin{array}{l}40 \\
31\end{array}$ & 9 & * \\
\hline Beech & 191 & 42 & 18 & 225 & 26 & 9 & $*$ \\
\hline Red maple & 204 & 23 & 16 & 212 & 17 & 4 & ns \\
\hline \multicolumn{8}{|l|}{ Top of canopy } \\
\hline $\begin{array}{c}\text { Bigtooth } \\
\text { aspen }\end{array}$ & 196 & 48 & 32 & 221 & 81 & 16 & ns \\
\hline Red oak & 174 & 35 & 11 & 212 & 53 & 7 & $*$ \\
\hline Red maple & 176 & 21 & 7 & 306 & 27 & 2 & $*$ \\
\hline
\end{tabular}

studies typically have found that maximum photosynthetic capacity is achieved at or near the completion of leaf expansion and is maintained for relatively short periods, on the order of a few days (e.g., Smillie, 1962; Fraser and Bidwell, 1974; O'Toole, Ludford, and Ozbun, 1977; Jurik et al., 1979) to a few weeks (e.g., Treharne, Cooper, and Taylor, 1968; Osman and Milthorpe, 1971; Aslam, Lowe, and Hunt, 1977). Photosynthetic capacity then declines until leaf death. In contrast, studies of evergreen conifers have shown that photosynthetic capacity is relatively constant over most of a growing season and gradually declines over the course of several growing seasons, until leaf death (Freeland, 1952; Ludlow and Jarvis, 1971; Schulze, Fuchs, and Fuchs, 1977).

Although declines in photosynthetic capacity with leaf age have been found in deciduous tree species (e.g., Logan, 1970; Dickmann, 1971; Samsuddin and Impens, 1979), patterns over the entire leaf lifespan typically have not been described. In fast-growing tree species that produce leaves over most of the growing season, there may indeed be a fairly rapid decline in photosynthetic capacity after a maximal rate is reached at the completion of leaf expansion, as is the case in cottonwood (Larson and Gordon, 1969) and in hybrid poplars (Dickmann, Gjerstad, and Gordon, 1975; Ceulemans and Impens, 1979; Reich, 1984). Studies of the effects of leaf age on photosynthesis of hardwood tree species in the field are rare, but suggest that slower-growing trees in the field, with leaf production mainly occurring during a spring flush of growth, may indeed have constant pho- 
tosynthetic capacity for longer periods, as found here. Schulze (1970) found photosynthetic capacity of sun-grown leaves of Fagus sylvatica to peak in late June and July, whereas shadegrown leaves exhibited a gradual increase in capacity from the end of leaf expansion to August; both sun and shade leaves then had rapid declines in capacity during late September and October. Benecke et al. (1981) also found photosynthetic capacity to be constant over most of the single growing season of needles in a deciduous conifer, Larix decidua. Experimentally-grown leaves of Coffea arabica had relatively constant photosynthetic capacity over most of leaf lifespan (Yamaguchi and Friend, 1979).

Photosynthetic capacity of leaves can be adjusted to the growth environment over evolutionary time (Mooney and Gulmon, 1979). The evolutionary development of the general pattern of short periods of maximum photosynthetic capacity in herbaceous species and in fast-growing woody species has been hypothesized to be related to the growth habit of these species (Mooney and Gulmon, 1982). In most such species, leaves are produced in relatively high light environments at the uppermost, growing tip of the plant. Continued growth of the plant or of surrounding vegetation typically leads to shading of a leaf after a few weeks. After a leaf becomes shaded and cannot take full advantage of a photosynthetic apparatus developed to operate in high light, resources such as nitrogen apparently are often shifted out of the leaf into new leaves (Small, 1972; Chapin, 1980). Thus, it may be economically advantageous, in terms of the plant's overall carbon budget, for a plant to produce relatively short-lived leaves with short periods in which high-light photosynthetic capacity is maintained at a maximal level (Mooney and Gulmon, 1982).

Relative to leaves of herbaceous species, tree leaves are often in fairly constant environments over most of their lifetimes. Many temperate zone tree species exhibit little production of leaves after an initial flush in the spring, so that there is little change in a leaf's light environment over the growing season. Hence, it may be most advantageous for such species to have leaves in which photosynthetic capacity is constant for most of the growing season, to match the relative constancy of conditions over the growing season. Similarly, evergreen tree leaves may also be viewed in terms of maximizing total carbon gain in a constant environment. Evergreenness additionally may be a manifestation of selective pressures to op- timize use of limited nutrients, in conjunction with optimizing carbon gain (Chapin, 1980; Chabot and Hicks, 1982).

Herbaceous species, deciduous woody species, and evergreen woody species represent ranges on a continuum of species with increasing periods in which the light environment of leaves is relatively constant. The pattern of constant photosynthetic capacity over most of the growing season seen in deciduous tree species of this study is consistent with the hypothesis that evolutionary response to growth in different light regimes results in different periods of duration of maximum photosynthetic capacity, with increasing constancy of the environment resulting in longer retention of maximum photosynthetic capacity. Additional evidence supporting this view was provided by Mooney et al. (1981), who found that desert annuals that experienced little decline in light availability over a growing season maintained maximum photosynthetic capacity longer than old-field annuals growing in environments that become more closed and shady over the course of the growing season.

In a practical sense, the pattern of nearly constant potential leaf CER from June to midSeptember in northern hardwood deciduous species is extremely useful to investigations of photosynthetic patterns and carbon dynamics. Since temperature response of CER of these tree species in northern lower Michigan does not change much during the growing season (Jurik, unpublished data), and assuming $\mathrm{CO}_{2}$ response of CER also does not vary, one can create a data set describing the multi-dimensional response of CER to environmental factors without introducing time as an independent variable, except for the relatively short periods of leaf expansion in late May and leaf senescence in late September. This means comparisons between species or habitats can be made with data collected at different times, assuming other conditions are similar; modeling of carbon dynamics of tree species throughout the season is also greatly simplified.

\section{LITERATURE CITED}

Ast.am, M., S. B. Lowe, and L. A. Hunt. 1977. Effect of leaf age on photosynthesis and transpiration of cassava (Manihot esculenta). Can. J. Bot. 55: 2288-2295.

Benicke, U., E. D. Schllzze, R. Matyssek, and W. M. Havranek. 1981. Environmental control of $\mathrm{CO}_{2}-$ assimilation and leaf conductance in Larix decidua Mill. I. A comparison of contrasting natural environments. Oecol. 50: 54-61.

Chulemans, R., ani) I. Impens, 1979. Studies of $\mathrm{CO}_{2}$ exchange processes, resistances to carbon dioxide and 
chlorophyll content during leaf ontogenesis in poplar. Biol. Pl. 21: 302-306.

Chabot, B. F., and D. J. Hicks. 1982. The ecology of leaf life spans. Ann. Rev. Ecol. Syst. 13: 229-259.

ChapIN, F. S., III. 1980. The mineral nutrition of wild plants. Ann. Rev. Ecol. Syst. 11: 233-260.

Dickmann, D. I. 1971. Photosynthesis and respiration by developing leaves of cottonwood (Populus deltoides Bartr.) Bot. Gaz. 132: 253-259.

- D. H. Guerstad, and J. C. Goridon. 1975. Developmental patterns of $\mathrm{CO}_{2}$ exchange, diffusion resistance and protein synthesis in leaves of Populus $x$ euramericana. In R. Marcelle [ed.], Environmental and biological control of photosynthesis, pp. 171-181. W. Junk, Publishers, The Hague.

Field, C., J. Merino, And H. A. Mooney. 1983. Compromises between water-use efficiency and nitrogenuse efficiency in five species of California evergreens. Oecol. 60: 384-389.

Fraser, D. E., and R. G. S. Bidwell. 1974. Photosynthesis and photorespiration during the ontogeny of the bean plant. Can. J. Bot. 52: 2561-2570.

FreElAND, R. O. 1952. Effect of age of leaves upon the rate of photosynthesis in some conifers. Pl. Physiol. 27: $685-690$.

Johnson, D. A., and M. M. Caldwell. 1974. Field measurements of photosynthesis and leaf growth rates of three alpine plant species. Arc. Alp. Res. 6: 245251 .

Jurik, T. W., J. F. Сhabot, and B. F. Сhabot. 1979. Ontogeny of photosynthetic performance in Fragaria virginiana. Pl. Physiol. 63: 542-547.

$\longrightarrow$, J. A. Weber, and D. M. Gates, 1984. Shortterm effects of $\mathrm{CO}_{2}$ on gas exchange of leaves of bigtooth aspen (Populus grandidentata) in the field. PI. Physiol. 75: 1022-1026.

LARSON, P. R., AND J. C. Gordon. 1969. Leaf development, photosynthesis, and $\mathrm{C}^{14}$ distribution in Populus deltoides seedlings. Amer. J. Bot. 56: 1058-1066.

LOGAN, K. T. 1970. Adaptations of the photosynthetic apparatus of sun- and shade-grown yellow birch (Betula alleghaniensis Britt.) Can. J. Bot. 48: 1681-1688.

Longistreth, D. J., J. A. Bolaños, and R. H. Goddard. 1985. Photosynthetic rate and mesophyll surface area in expanding leaves of Alternanthera philoxeroides grown at two light levels. Amer. J. Bot. 72: 14-19.

Lunlow, M. 1975. Effect of water stress on the decline of leaf net photosynthesis with age. In R. Marcelle [ed.], Environmental and biological control of photosynthesis, pp. 123-134. W. Junk, Publishers, The Hague.

- AND P. O. Jarvis. 1971. Photosynthesis in Sitka spruce (Picea sitchensis Bong. Carr). I. General characteristics. J. Appl. Ecol. 8: 925-953.

Mooney, H. A., And S. L. Gulmon. 1979. Environmental and evolutionary constraints on the photo- synthetic characteristics of higher plants. In Solbrig, O. T., S. Jain, G. B. Johnson, and P. H. Raven [eds.], Topics in plant population biology, pp. 316-337. Columbia Univ. Press, N.Y.

__._. AND S. L. Gulmon. 1982. Constraints on leaf structure and function in reference to herbivory. BioScience 32: 198-206.

- C. Field, S. L. Gulmon, and F. A. Bazzaz. 1981. Photosynthetic capacity in relation to leaf position in desert versus old-field annuals. Oecol. 50: 109-112.

Osman, A. M., Ani) F. L. Milthorpe. 1971. Photosynthesis of wheat leaves in relation to age, illuminance and nutrient supply. II. Results. Photosynthetica 5: $61-70$.

O'ToOle, J. C., P. M. Ludford, and J. L. Ozbun. 1977. Gas exchange and enzyme activity during leaf expansion in Phaseolus vulgaris L. New Phytol. 78: 565571.

REICH, P. B. 1984. Relationships between leaf age, irradiance, leaf conductance, $\mathrm{CO}_{2}$ exchange, and water use efficiency in hybrid poplar. Photosynthetica 18: 445-453.

SAMSUIDdin, Z., AND I. ImPENS. 1979. The development of photosynthesis rate with leaf age in Hevea brasiliensis Muell. Arg. clonal seedlings. Photosynthetica 13: 267-270.

Schulze, E. D. 1970. Der CO-Gaswechsel der Buche (Fagus silvatica L.) in Abhangigkeit von den Klimafaktoren im Freiland. Flora 159: 177-232.

$\longrightarrow$, M. FuCHS, AND M. I. FuchS. 1977. Spacial distribution of photosynthetic capacity and performance in a mountain spruce forest of northern Germany. III. The significance of the evergreen habit. Oecol. 30: 239-248.

SMALL, E. 1972. Photosynthetic rates in relation to nitrogen recycling as an adaptation to nutrient deficiency in peat bog plants. Can. J. Bot. 50: 2227-2233.

Smillie, R. M. 1962. Photosynthetic and respiratory activities of growing pea leaves. Pl. Physiol. 37: 716721.

Treharne, K. J., J. P. CoOper, ANd T. H. TAylor. 1968. Growth response of orchard grass (Dactylis glomerata L.) to different light and temperature environments. II. Leaf age and photosynthetic activity. Crop Sci. 8: 44l-445.

von Caemmerer, S., and G. D. Farquhar, 1981. Some relationships between the biochemistry of photosynthesis and the gas exchange of leaves. Planta 153: 376387.

Whale, D. M. 1983. Seasonal variation in the gas exchange characteristics of Primula species. Oecol. 59: 377-383.

Yamagiuchl, T., and D. J. C. Friend. 1979. Effect of leaf age and irradiance on photosynthesis of Coffea arabica. Photosynthetica 13: 271-278. 